\title{
Early Evaluation of Renal Function in High-Risk Patients after Off-Pump Coronary Artery Bypass Grafting
}

\author{
Istiaq Ahmed, AM Asif Rahim, Khawaja Nasir Uddin Mahmood, Manzil Ahmad \\ Department of Cardiac Surgery, NICVD, Dhaka
}

Key Words : Ischaemic heart disease, Renal failure, Coronary artery bypass surgery.

\begin{abstract}
:
Background: Cardiopulmonary bypass $(C P B)$ is an unphysiological state and widely regarded as an important contributor to renal failure. Despite improvement in cardiopulmonary bypass technique, anesthesia and intensive care, perioperative renal dysfunction still represents a significant and potentially lethal complication after coronary artery bypass graft surgery (CABG). Renal dysfunction is a serious complication of coronary revascularization with CPB and results in increased morbidity, mortality and prolonged hospital stay. We compared the incidence of perioperative renal dysfunction in patients who underwent $C A B G$, on-pump and off-pump (OPCAB).
\end{abstract}

Methods: A total of 60 high -risk patients with ischaemic heart diseases were included in the study who underwent CABG. Out of the total 60 patients, 30 were in the Off-pump group (Group A) and the rest 30 were in the On-pump group (Group B). They were diagnosed as high-risk patients considering serum creatinine level $>1.7 \mathrm{mg} / \mathrm{dl}$ with age $\geq 60$ years, ejection fraction $30-40 \%$. Renal function was evaluated in both groups preoperatively and postoperatively (on 1st, 2nd and 7th postoperative day) and compared between two groups.

Results: One patient in the On-pump group died on 6th postoperative day. Preoperative renal parameters were also similar and showed no statistically significant difference. So both groups were comparable. Comparison of renal parameter in OPCAB and on-pump CABG between preoperative

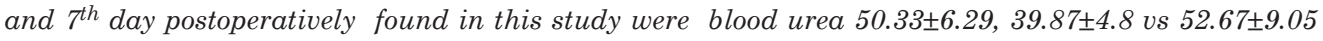

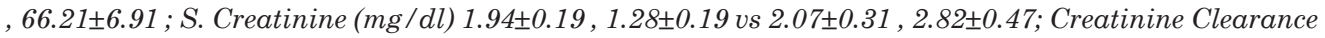

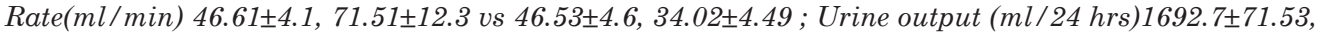
$1755.7 \pm 82.91$ vs $1591.2 \pm 78.76,1492.1 \pm 196.29$ all are statistically significant $(p<0.05)$. Mean period of mechanical ventilation, ICU stay and total postoperative hospital stay were significantly greater in On-pump group. One patient of Group $-B$ died due to multi organ failure including acute renal failure on 6th postoperative day (3.3\%) ( $p>0.05)$. Statistically significant difference of renal parameters in different postoperative days showed evidence of well preservation of renal function in OPCAB.

Conclusion: Adaptation of OPCAB offers better preservation of renal function as well as better early postoperative outcome specially in high-risk CABG patients.

(Cardiovasc. j. 2016; 9(1): 23-30)

\section{Introduction:}

Coronary artery bypass grafting is one of the procedures with the highest impact in the history of medicine. No other operation has led to more lives prolonged and been better characterized with respect to its short and long term outcomes. CABG constitutes the keystone of adult cardiac surgery. ${ }^{1}$ Cardiopulmonary bypass is an unphysiological state and widely regarded as an important contributor to renal failure. ${ }^{2}$ Despite improvement in CPB technique, anesthesia and intensive care, preoperative renal dysfunction still represents a significant and potentially lethal complication after cardiac operations. ${ }^{3}$ Renal dysfunction is a serious complication of coronary revascularization with $\mathrm{CPB}$ and results in increased morbidity, mortality and prolonged hospital stay. ${ }^{4}$

Off-pump coronary artery bypass grafting operation on a beating heart significantly reduces oxidative stress and suppresses the inflammatory reaction associated with the use of CPB. ${ }^{5}$ OPCAB is considered renoprotective. ${ }^{6}$ It is associated with lower in- hospital mortality and complication rates than On-pump CABG and also reduces length of hospital stay, incidence of atrial fibrillation and wound infections. ${ }^{7,8}$

Address of correspondence: Dr. Istiaq Ahmed, Department of Cardiac Surgery, National Institute of Cardiovascular Diseases, Dhaka, Bangladesh. email: istimed48@yahoo.com 
OPCAB has been proposed as a means of minimizing many of the alterations caused by $\mathrm{CPB}$ to reduce the risk of postoperative renal insufficiency. Avoidance of the pump may result in better preservation of glomerular and tubular function with less evidence of damage. The population of patients referred for CABG has substantially changed in the last years. The progress in medical therapy and interventional cardiology coupled with the increase in life expectancy and the widespread availability of cardiac surgery facilities have shifted toward the high risk profile of patients proposed for surgical myocardial revascularization and there is clear evidence that the cardiac and the systemic preoperative status of CABG patient have become progressively more complex, and that high risk patients represent now a substantial proportion of surgical candidates. ${ }^{9}$

Any patient with one or more of the following characteristics was considered to be at high-risk for early mortality and morbidity. Age of 75 years or more, ejection fraction lower than $40 \%$, serum creatinine level of $150 \mu \mathrm{mol} / \mathrm{l}$ or higher. ${ }^{10}$ Incidence of postoperative renal dysfunction in CABG patients is about $10 \%$ and renal complication in high-risk subgroup of patients underwent bypass surgery was $3.3 \%$ in off-pump and $5.4 \%$ in onpump. ${ }^{11,12}$ Though the incidence of acute renal failure(ARF) requiring dialysis after open heart operation is relatively low ( $1 \%$ to $5 \%$ ) but it is associated with a mortality rate up to $60 \% .{ }^{13}$ Elevation in serum creatinine $(\mathrm{Cr})$ has been a commonly used marker of ARF in hospitalized patients. ${ }^{14}$

Postoperative renal dysfunction markedly affects the surgical outcome of these high-risk patients in terms of increase the length of ICU stay, hospital stay and cost of surgery, last but not least the rate of mortality. To improve the clinical outcome of these high-risk patients for renal impairment now off-pump coronary artery bypass grafting is being performed frequently.

\section{Methods:}

This prospective clinical study was performed in the department of Cardiac surgery, National Institute of Cardiovascular Diseases (NICVD) from July 2006 to June 2008. A total of sixty high-risk patients aged from 45 to 68 years undergoing coronary artery bypass grafting were enrolled in the study. Study population was divided in two groups- Group A- undergoing off pump CABG and Group B undergoing on pump CABG. In each group thirty patients were included consecutively. They were diagnosed as high risk patients considering serum creatinine $\geq 1.7$ with age $\geq 60$ years, ejection fraction $30-40 \%$. Patients with coexisting valve disease and congenital heart disease were excluded from the study. The aims and objectives of this study were to evaluate the renal function in highrisk patients after off-pump coronary artery bypass grafting, to compare preoperative renal function between off-pump and on-pump CABG patients, to compare renal function in different postoperative days (POD1, POD2 and POD7) between off-pump and on-pump CABG and to observe changes of renal function from preoperative period to postoperative periods in each group.

The objective of the study was discussed in details with the patients before their decision to enroll themselves into the study. A detailed clinical history was taken from the patient regarding smoking, diabetes, hypertension, dyslipidemia. Relevant physical examination was also done in all the cases. All the patients were categorized according to NYHA classification preoperatively. Ultimately all the sixty patients, thirty in each group underwent CABG. Their renal functions were evaluated preoperatively as well as postoperatively on $1^{\text {st }} \mathrm{POD}, 2^{\text {nd }} \mathrm{POD}$ and $7^{\text {th }} \mathrm{POD}$. Blood urea, serum creatinine, creatinine clearance rate and urine output were considered as parameters for evaluation of renal function. During observation, total operating time was also recorded in each patient. Regarding post operative events, total ICU stay, period of mechanical ventilation and total hospital stay were recorded. Major post operative complications like acute renal failure, need for dialysis, prolonged ventilation $>48 \mathrm{hrs}$, deep sternal would infection, respiratory infection \& number of death were also recorded. Each patient was followed-up up to 3 months. All the relevant collected data were collected from each participant using predesigned data collection sheets (proforma). All the collected data were compiled on a master chart first and then organized by using scientific calculator and standard statistical formulas. Statistical analyses of the results were done by computer software device as statistical 
packages for social scientist (SPSS). The results were presented in tables. For comparison between two groups, the study outcomes were evaluated regarding unpaired ' $t$ ' test and chi-square test. A "p" value $<0.05$ was considered as significant.

\section{Results:}

The mean age was $57.03 \pm 4.35$ vs. $54.47 \pm 4.47$, most of the patients belong to 50-59 years ( $\mathrm{p}>0.05)$. Most of the patients were in NYHA class-II $53.3 \%$ vs. $46.7 \%$ in both groups. Regarding risk factors hypertension was on the top ( $60 \%$ vs. $70 \%$ ), among others smoking ( $56.7 \%$ vs. $63.3 \%)$, diabetes mellitus ( $70 \%$ vs. $30 \%)$, angina ( $26.7 \%$ vs. $36,7 \%)$ and dyslipidaemia ( $60 \%$ vs. $63.3 \%)$ all were insignificant statistically $(\mathrm{p}>0.05)$ except diabetes mellitus. Comparison of high-risk indicators between off- pump and on- pump CABG patients was: age $\geq 60$ yrs ( $33.3 \%$ vs. $16.7 \%$ ), EF 30 $40 \%$ (26.7\% vs. $33.3 \%$ ), renal dysfunction (S. creatinine $\geq 1.7 \mathrm{mg} / \mathrm{dl})(100 \%$ vs. $100 \%)$.

Mean \pm SD of total operative time in minute between groups were $222.67 \pm 21.88$ vs. $317.67 \pm$
48.69 statistically found highly significant $(p=0.001)$. Comparison of postoperative events between off-pump and on pump CABG patients Mean \pm SD of period of mechanical ventilation in hours $(9.87 \pm 1.68$ vs. $17.57 \pm 6.34, \mathrm{p}=0.001)$. ICU stay in days ( $3.17 \pm 0.83$ vs. $4.47 \pm 1.17, \mathrm{p}=0.001)$, total hospital stay in days $(9.27 \pm 1.28$ vs $11.43 \pm 2.49$, $\mathrm{p}=0.001)^{\mathrm{S}}$ between group $-\mathrm{A} \&$ group-B. Regarding postoperative complications acute renal failure ( $3.3 \%$ vs. $13.3 \%, p=0.176)$, dialysis was needed $(0 \%$ vs. $6.7 \% \mathrm{p}=0.245$ ), deep sternal wound infection (3.3\% vs. $13.3 \%, \mathrm{p}=0.176)$, respiratory infection $(3.3 \%$ vs. $16.7 \%, \mathrm{p}=0.097)$, death only 1 in group-B $(3.3 \%, \mathrm{p}=0.5)$.

No significant difference regarding baseline values of all renal parameters (pre-operative values) between two groups. But statistically significant difference were observed regarding blood urea , serum creatinine, creatinine clearance rate and urine output in POD1, POD2 and POD7 between two groups.

Table-I

Comparison of blood urea $(\mathrm{mg} / \mathrm{dl})$ in two groups of study population $(n=60)$.

\begin{tabular}{lccc}
\hline Blood UreaMg/dl & $\begin{array}{c}\text { Group A(n=30) } \\
\text { Mean } \pm \text { SD }\end{array}$ & $\begin{array}{c}\text { Group B(n=30) } \\
\text { Mean } \pm \text { SD }\end{array}$ & p- value \\
\hline Preoperative & $50.33 \pm 6.29$ & $52.67 \pm 9.05$ & 0.251 \\
POD1 & $60.33 \pm 6.42$ & $73.9 \pm 12.22$ & 0.001 \\
POD2 & $60.43 \pm 6.5$ & $75.3 \pm 16.61$ & 0.001 \\
POD7 & $39.87 \pm 4.8$ & $66.21 \pm 6.91$ & 0.001 \\
\hline
\end{tabular}

$\mathrm{p}$ value reached from paired-t test, POD- Post operative day.

Table-II

Comparison of serum creatinine $(\mathrm{mg} / \mathrm{dl})$ in two groups of study population $(n=60)$.

\begin{tabular}{lccc}
\hline Serum creatinine & $\begin{array}{c}\text { Group A(n=30) } \\
\text { Mean } \pm \text { SD }\end{array}$ & $\begin{array}{c}\text { Group B(n=30) } \\
\text { Mean } \pm \text { SD }\end{array}$ & p- value \\
\hline Preoperative & $1.94 \pm 0.19$ & $2.07 \pm 0.31$ & 0.053 \\
POD1 & $2.31 \pm 0.37$ & $3.49 \pm 0.8$ & 0.001 \\
POD2 & $2.27 \pm 0.43$ & $3.57 \pm 0.93$ & 0.001 \\
POD7 & $1.28 \pm 0.19$ & $2.82 \pm 0.47$ & 0.001 \\
\hline
\end{tabular}

$\mathrm{p}$ value reached from paired-t test, POD- Post operative day. 
Table-III

Comparison of creatinine clearance rate $(\mathrm{ml} / \mathrm{min})$ in two groups of study population $(n=60)$.

\begin{tabular}{lccc}
\hline Creatinine Clearance Rate & $\begin{array}{c}\text { Group A(n=30) } \\
\text { Mean } \pm \text { SD }\end{array}$ & $\begin{array}{c}\text { Group B }(\mathrm{n}=30) \\
\text { Mean } \pm \text { SD }\end{array}$ & p- value \\
\hline Preoperative & $46.61 \pm 4.1$ & $46.53 \pm 4.6$ & 0.947 \\
POD1 & $39.7 \pm 6.01$ & $28.17 \pm 5.36$ & 0.001 \\
POD2 & $40.67 \pm 7.21$ & $27.74 \pm 5.27$ & 0.001 \\
POD7 & $71.51 \pm 12.3$ & $34.02 \pm 4.49$ & 0.001 \\
\hline
\end{tabular}

$\mathrm{p}$ value reached from paired-t test, POD- Post operative day.

Table-IV

Comparison of urine output (ml/24 hours) in two groups of study population $(n=60)$.

\begin{tabular}{lccc}
\hline URINE output & Group A(n=30) & Group B(n=30) & p- value \\
& Mean \pm SD & Mean \pm SD & \\
\hline Preoperative & $1692.7 \pm 71.53$ & $1591.2 \pm 78.76$ & 0.001 \\
POD1 & $1619.3 \pm 181.18$ & $1480.7 \pm 170.68$ & 0.003 \\
POD2 & $1631 \pm 90.91$ & $1383.7 \pm 319.21$ & 0.001 \\
POD7 & $1755.7 \pm 82.91$ & $1492.1 \pm 196.29$ & 0.001 \\
\hline
\end{tabular}

$\mathrm{p}$ value reached from paired-t test, POD- Post operative day.

\section{Discussion:}

The population of patients referred for coronary artery bypass grafting (CABG) has substantially changed world-wide as wells in our country in the last years. The progress in medical therapy and intervention cardiology coupled with the increase in life expectancy and the widespread availability of cardiac surgery facilities have shifted towards the high-risk profile patients for surgical revascularisation. ${ }^{9}$

National Institute of Cardiovascular diseases, Dhaka, Bangladesh has been performing the central role in the field of cardiac surgery countrywide. CABG has been performing from 1985 and off pump coronary artery bypass grafting (OPCAB) is being performed since 1997 in NICVD. In 2007 a total of 186 CABG were performed in NICVD, among them OPCAB 105(56\%) and onpump 81(44\%).

The present study was elicited by the need to improve the clinical outcome of high-risk coronary artery bypass patients by applying different surgical approaches to different patients. The aim of this clinical prospective study was to compare the postoperative renal function in high-risk patients undergoing on-pump \& off-pump CABG. Maximum number was found in the age group of 50-59 years in both the off-pump and on-pump groups. On the contrary a study done by Calafiore et al. had mean age $64.4 \pm 9.6$ years for $\mathrm{OPCAB}$ and $63.3 \pm 9.7$ years for on-pump CABG patients. ${ }^{15}$ These higher mean ages of patients undergoing bypass surgery in developed country may explain the improved \& sophisticated surgical technique \& ICU support as well as increase in life expectancy which has enabled them to choose more \& more elderly patients for bypass grafting. In our study risk factors were compared between off-pump \& onpump CABG groups. In this study 17 (56.7\%) patients in group A \& 19 (63.3\%) patients in group B were smoker. No significant difference exists in between two groups. Arom et al. found $22 \%$ \& $18.8 \%$ smoker in off-pump \& on- pump group respectively. ${ }^{16}$ This incidence is much higher in our study. This may explain the lack of awareness about the hazards of smoking in our country. In the present study $21(70 \%)$ patients in OPCAB group \& $9(30 \%)$ patients in on- pump group had diabetes mellitus. The difference was statistically significant. On the other hand, Arom et al. found diabetes in $33.3 \%$ \& $33.8 \%$ patients in OPCAB \& on-pump group respectively. ${ }^{16}$ A study on 1570 high-risk patients by chamberlain et al. reported hypertension was $60.7 \%$ and $61.9 \%$ in off-pump and on- pump CABG group respectively and 
hyperlipidemia was found $75.2 \% \& 68.3 \%$ in offpump and on-pump group respectively. ${ }^{10}$ On the other hand, in this study, hypertension was found in $18(60 \%) \& 21(70 \%)$ patients in off-pump and onpump CABG groups respectively and hyperlipidemia was found in $18(60 \%)$ patients and $19(63.3 \%)$ in off-pump and on-pump group respectively. In the present study, among the common risk factors significant difference exists between the two groups regarding diabetes mellitus. In both groups predominant risk factors were smoking, diabetes mellitus, hypertension and hyperlipidemia .

High-risk patients in the study were found elderly $\geq 60$ years $(33.3 \%$ vs. $16.7 \%)$, ejection fraction between $30-40 \%$ (26.7\%vs 33.3\%), renal dysfunction (S.creatinine $\geq 1.7 \mathrm{mg} / \mathrm{dl}$ ) (100\% vs $100 \%)$ in offpump vs on-pump group respectively. The highrisk indicators between off-pump and on-pump $\mathrm{CABG}$ were almost comparable. The above findings showed that the preoperative patient characteristics regarding age, NYHA functional class, risk factors of $\mathrm{CAD}$ and cardiopulmonary functional status were almost similar to the studies conducted by other authors. ${ }^{10,12}$ These features have no significant influence on peroperative and postoperative clinical outcome. Comparison of peroperative variables between groups demonstrate that total operation time in off-pump group was significantly less than that of on-pump group in this study. The difference was statistically significant. Arom et al. reported that total operation time was 175(36) min and 235(65) min in off-pump \& on-pump group respectively, which corresponds with our study. ${ }^{16}$

Several postoperative variables have been compared between the two groups. In this study mean ventilation period in off-pump group was $9.87 \pm 1.68 \mathrm{hrs}$ and in on-pump group was $17.57 \pm 6.34$ hrs. The difference was statistically significant. That is OPCAB procedures to be better tolerated by the patients; ventilation time was significantly higher in on-pump group. According to Ascione et $a l$. ventilation time was $12.5 \pm 7.1$ hours and $11.8 \pm 9.6$ hours in on-pump and off-pump group respectively. ${ }^{13}$ But Arom et al. reported significantly higher ventilation time in on-pump group. ${ }^{16}$ Ventilation time was 19 hours in on-pump vs 9 hours in off-pump group $(\mathrm{p}<0.001)$. Cleveland et al. and Plomondon et al. also showed significantly higher ventilation tine in on-pump group. ${ }^{18,19}$ This finding is similar to our study. On the other hand, mean period of total ICU stay in OPCAB and on-pump CABG groups were $3.17 \pm 0.83$ days and $4.47 \pm 1.17$ days respectively. The difference in two groups was statistically significant. Calafiore et al. showed in a study that ICU stay was 13.5 $\pm 16.6 \mathrm{hrs}$ in off-pump and $16.2 \pm 15.3 \mathrm{hrs}$ in onpump group, whereas Boyd et al. reported ICU stay (hrs) $24 \pm 10.9 \mathrm{hrs}$ in off-pump and $36.6 \pm 33.5 \mathrm{hrs}$ in on-pump group. ${ }^{15,20}$ These findings were similar to our study because in all these study on-pump group required more ICU stay. Total postoperative hospital stay $9.27 \pm 1.28$ days and $11.43 \pm 2.49$ days in off-pump and on-pump group respectively. The difference is statistically significant $(\mathrm{p}<0.001)$. Ascione et al. reported length of hospital stay $5.84 \pm 1.5$ days and $7.36 \pm 3$ days in off-pump vs onpump group respectively. ${ }^{21}$ It was statistically significant $(p<0.03)$. This finding corresponds to our study. Thus the mean period of mechanical ventilation, ICU stay and total postoperative hospital stay were significantly greater in on-pump group than off-pump group. All these reflect definite clinical advantage as well as favorable economic outcome associated with off-pump group of patients. In this prospective clinical study, the patients had been followed up to 3 months. Among the total sixty patients, one patient in on-pump group died on $6^{\text {th }}$ POD due to multiorgan failure. Mortality rate was $0 \%$ versus $3.3 \%$ in off-pump and on-pump group respectively and that was not statistically significant. Arom et al. reported operative mortality in high-risk patient was $28.5 \%$ in onpump versus $7.7 \%$ in off-pump group $(\mathrm{p}=0.008) .{ }^{16}$ This finding did not correspond to our study.

In the present study, postoperative morbidities were acute renal failure (3.3\% vs $13.3 \%)$, need for dialysis ( $0 \%$ vs $6.7 \%$ ), deep sternal wound infection (3.3\% vs $13.3 \%)$, respiratory tract infection $(3.3 \%$ vs $16.7 \%$ ) in off-pump group and on-pump group respectively. None of them required prolonged ventilation ( $>48$ hours) in either group. In comparison of major postoperative complications statistically significant difference was not observed in between two groups. Yokoyama et al. in a study on off-pump vs on-pump coronary artery bypass in high-risk group showed renal complication was $3.3 \%$ vs $5.4 \%$, prolonged ventilation was $3.7 \%$ vs 
$6.6 \%$ in off-pump vs on-pump CABG groups respectively. ${ }^{12}$ In a study by Ascione et at. reported acute renal failure (5.9\% vs $15.8 \%)$, infective complication (5.9\% vs $7.42 \%$ ) in off-pump and onpump group respectively. ${ }^{13}$

Renal function was compared between OPCAB and on-pump groups both preoperatively and postoperatively. Preoperative mean blood urea values showed no statistically significant difference in between two groups. But the mean blood urea values on the $1^{\text {st }}, 2^{\text {nd }}$ and $7^{\text {th }}$ POD showed significantly higher level in on-pump group. Mean preoperative serum creatinine level was $1.94 \pm 0.19$ $\mathrm{mg} / \mathrm{dl}$ and $2.07 \pm 0.31 \mathrm{mg} / \mathrm{dl}$ in group A and group B respectively. The difference in preoperative values in two groups was not statistically significant. Mean serum creatinine level in the $1^{\text {st }}$ POD, $2^{\text {nd }}$ POD and $7^{\text {th }}$ POD showed significantly higher level in on-pump group than off-pump group. Here the difference in the postoperative values in two groups was statistically significant. Promodh et al. found that serum creatinine levels increased progressively in both groups from preoperatively to $24 \mathrm{hrs}$ postoperatively and thereafter decreased by $48 \mathrm{hrs}$ postoperatively. ${ }^{22}$ This finding was similar to our observation. But Tang et al. reported in their study that no significant difference in serum creatinine or blood urea was detected between the two groups during the study period with both parameters staying within the normal range throughout. ${ }^{6}$ Comparison of creatinine clearance rate $(\mathrm{ml} / \mathrm{min})$ in two groups was also evaluated preoperatively and of different postoperative days. No significant difference was found in preoperative values between group A and group B patients. But significant differences were found in values on $1^{\text {st }}, 2^{\text {nd }}$ and $7^{\text {th }}$ POD. Tang et al. advocated in their study that there was no significant difference in OPCAB and on-pump group regarding creatinine clearance. ${ }^{6}$ Loef et al. also found no significant difference in creatinine clearance rate throughout the entire observation period. ${ }^{4}$ Promodh et al. found statistically significant decrease in creatinine clearance in both groups from preoperatively to $24 \mathrm{hrs}$ postoperatively. ${ }^{22}$ In case of off-pump group creatinine clearance rate $(\mathrm{CcR})$ increase and reached to preoperative level by $48 \mathrm{hrs}$ but in onpump group gradual increase of $\mathrm{CcR}$ but not reach up to preoperative level.
Comparison of 24 hours urine output (ml) in two groups were done preoperatively as well as on different postoperative days. Here it was observed that in all the periods 24 hours urine output was lower significantly in on-pump group than off-pump group. Loef et al. suggesting that renal perfusion was equally adequate in the postoperative periods as urine output did not differ between groups in his study. ${ }^{4}$ Gerritsen et al. reported that mean preoperative urine output was significantly lower than the mean urine output during and after the surgery in both groups. ${ }^{23}$ Besides comparing renal parameters in between OPCAB and on-pump CABG groups, time course of renal variables were also observed. Regarding blood urea levels, OPCAB and on-pump groups had almost similar baseline values (preoperative value) and in course of time values increased on $1^{\text {st }} \mathrm{POD}$ and $2^{\text {nd }} \mathrm{POD}$ in both groups and blood urea level declines on consecutive POD in OPCAB group but remained elevated in on-pump group. But statistically significant difference remained between preoperative blood urea level and value on $7^{\text {th }}$ POD in both groups. Tang et al. stated that no significant difference in blood urea was detected between the groups during the study period (preoperative to $5^{\text {th }}$ POD) ${ }^{6}$ Trend of change in serum creatinine level was observed in both OPCAB and on-pump group. Comparison over time between groups showed no significant difference in baseline values between two groups. Serum creatinine was increased in two groups on $1^{\text {st }}$ POD. Thereafter creatinine value declined in group A over time and reached lower than preoperative value but at each time point ( $2^{\text {nd }}$ and $\left.7^{\text {th }} \mathrm{POD}\right)$ creatinine value remained elevated in group B. There was highly significant difference between preoperative and $7^{\text {th }}$ POD serum creatinine value in group B. Ascione et al. reported similar initial changes as in our study regarding serum creatinine but they followed each patient for only $60 \mathrm{hrs}$ postoperatively. ${ }^{13}$ Change of $\mathrm{CcR}$ over each point of time was observed in both groups. Preoperative $\mathrm{CcR}$ in both group showed no statistically significant difference. During the postoperative period $\mathrm{CcR}$ reduced in both groups significantly on $1^{\text {st }}$ and $2^{\text {nd }}$ POD. Thereafter CcR gradually increased over time. In OPCAB group $\mathrm{CcR}$ reached a level higher than preoperative level which was statistically highly significant. In on-pump group CcR was also elevated from $1^{\text {st }}$ POD to $7^{\text {th }}$ POD, 
but reached a level below the preoperative level. Promodh et al. reported similar initial changes as in our study, regarding CcR but they followed for only 48 hrs postoperatively. ${ }^{22}$ Ascione et al. also reported that at 24 and 48 hrs postoperatively the creatinine clearance values decreased significantly in the on-pump group, reaching levels markedly lower than preoperative levels. ${ }^{21}$ Conversely, in the off-pump group the values returned to preoperative levels at both 24 and 48 hrs postoperatively. Their findings were almost similar to our study is case of on-pump group but differ is case of off-pump group. They reported that CcR returned to preoperative level at both 24 and 48 hrs but in our study level decreased in POD1 then slightly increase in $48 \mathrm{hrs}$ and returned to preoperative level by $7^{\text {th }}$ POD.

From the above discussion it is conceived that patients in both groups were similarly distributed in regards of age, risk factors, NYHA class, risk indicators. Preoperative renal parameters were also similar and showed no statistically significant difference. So both groups were comparable. But the renal parameters showed significant difference in different postoperative periods in two groups with evidence of well preservation of renal function in off-pump group that showed significant impact on postoperative outcome. So our data furnish substantial evidence that the adaptation of OPCAB confer significant clinical advantages in high-risk CABG patients.

\section{Conclusion:}

This prospective clinical study on high-risk patients undergoing on-pump and off-pump CABG revealed significant difference in renal parameters on different postoperative days. The trend of changes in renal parameters on different postoperative days also showed significant preservation of renal function in OPCAB group. On the other hand, cardiopulmonary bypass has detrimental effect on renal function and required longer duration of mechanical ventilation, ICU stay and hospital stay. So it can be concluded that OPCAB offers better preservation of renal function as well as better early postoperative outcome specially in renal high-risk CABG patients.

\section{Limitation of the Study:}

We had some limitations in the study like- Period of study was short; Sample size was small; Lack of proper investigation facilities (like microalbuminto-creatinine ratio, $N$-acetyl- $\beta$-D-glucosaminidase (NAG), $\alpha_{1}$-macroglobulin, glutathione transferase$\alpha$, fractional excretion of sodium $\left(\mathrm{EF}_{\mathrm{Na}}\right)$, retinolbinding protein).

\section{References:}

1. Ruel M and Sellke FW. Coronary artery bypass grafting. In: Sellke FW, Nido PJD, Swanson SJ.Eds. Sabiston and Spencer Surgery of Chest. $7^{\text {th }}$ ed, Pennsylvania, USA: Elsevier Saunders; 2005:1459-1461.

2. Raghuram AR. Off-Pump CABG: A Review. The Internet Journal of Cardiology 2003; 2: 601-617.

3. Regragui IA, Izzat MB, Birdi I, Lapsley M, Bryan A, Angelini GD. Cardiopulmonary bypass perfusion temperature dose not influence perioperative renal function. Ann Thorac Surg 1995; 60: 160-164.

4. Loef BG, Epema AH, Navis G, Ebels T, Oeveren WV, Henning RH. Off-pump coronary revascularisation attenuates transient renal damage compared with onpump coronary revascularisation. Chest 2002; 121: 1190-1194.

5. Matata BM, Sosnowski AW, Galinanes M. Off-Pump bypass graft operation significantly reduces oxidative stress and inflammation. Ann Thorac Surg 2000; 69: 785-791.

6. Tang ATM, Knott J, Nanson J, Hsu J, Haw MP, Ohri SK. A prospective randomized study to evaluate the renoprotective action of beating heart coronary surgery in low risk patients. Eur J Cardio-thorac 2002; 22: 118-112.

7. Hannan EL, Wu C, Smith CR, Higgins RSD, Carlson RE, Culliford AT, et al. Off-Pump versus on-pump coronary artery bypass graft surgery: Differences in short-term outcomes and in long-term mortality and need for subsequent revascularization. Circulation 2007;116: 1145-1152.

8. Reston JT, Treager SJ, Turkelson CM. Meta-analysis of short-term and mid-term outcomes following offpump coronary artery bypass grafting. Ann Thorac Surg 2003; 76: 1510-1515.

9. Gaudino M, Glieca F, Alessandrini F, Nasso G, Pragliola C, Luciani N, et al. High-risk coronary artery bypass patient: Incidence, surgical strategies \& results. Ann Thorac Surg 2004; 77: 574-580.

10. Chamberlain MH, Ascione R, Reeves BC, Angelini GD. Evaluation of the effectiveness of off-pump coronary artery bypass grafting in high-risk patients; an observational study. Ann Thorac Surg 2002; 72: 1866-1873. 
11. Bojar RM. Manual of perioperative care in adult cardiac surgery. $4^{\text {th }}$ edn. Massachusetts, USA: Blackwell; 2005: 470- 471.

12. Yokoyama T, Baumgartner FJ, Gheissari A, Capouya ER, Panagiotides GP, Declusin RJ. Off-Pump versus On-Pump coronary bypass in high-risk subgroups. Ann Thorac Surg 2000; 70: 1546-1550.

13. Ascione R, Nason G, Al-Ruzzeh S, Ko C, Ciulli F, Angelini GD. Coronary revascularization with or without cardiopulmonary bypass in patients with preoperative nondialysis-dependent renal insufficiency. Ann Thorac Surg 2001; 72: 2020-2025.

14. Brown JR, Cochran RP, Dacey LJ, Ross CS, Kunzelman KS, Dunton RF, et al. Perioperative increases in serum creatinine are predictive of increased 90 day mortality after coronary artery bypass graft surgery. Circulation 2006; 114: 409-413.

15. Calafiore AM, DiMauro M, Contini M, Giammarco GD. Myocardial revascularisation with and without cardiopulmonary bypass in multivessel disease: impact of the strategy on early outcome. Ann Thorac Surg 2001; 72: 456-463.

16. Arom KV, Flavin TF, Emery RW, Kshettry VR, Janey PA, Petersen TJ. Safety and efficacy of off-pump coronary artery bypass grafting. Ann Thorac Surg 2000; 69: $704-710$.
17. Hernandez F, Cohn W, Baribeau YR, Tryzelaar JF, Charlessworth DC, Clough RA. In-hospital outcomes of off-pump versus on-pump coronary artery bypass procedures: a multicenter experience. Ann Thorac Surg 2001; 72: 1528-1534.

18. Cleveland JC, Shroyer ALW, Chen AY, Petenson E, Groven FL. Off-pump coronary artery bypass grafting decrease risk adjusted mortality and morbidity. Ann Thorac Surg 2001; 72: 1282-1289.

19. Plomondon ME, Cleveland JC, Ludwig ST. Off-pump coronary artery bypass is associated with improved riskadjusted outcomes. Ann Thorac Surg 2001;72: 114-119.

20. Boyd WD, Desai ND, Rizzo DF, Novick DR, Mckenzie JN, Menkis AH. Off-pump surgery decreases postoperative complication and resource utilization in the elderly. Ann Thorac Surg 1999; 68: 1490-1493.

21. Ascione R, Lloyd CT, Underwood MJ, Gomes WJ, Angelini GD. On-Pump versus Off-Pump coronary revascularization: evaluation of renal function. Ann Thorac Surg 1999; 68: 493-498.

22. Pramodh KV, Muralidhar K. Renal function following CABG: on-pump vs off-pump. Cardiovasc Surg 2003; 19: $169-173$

23. Gerritsen WBM, Boven V, Drieessen AHG, Haas FJLM, Aarts LPHJ. Off-pump versus on-pump coronary artery bypass grafting: oxidative stress and renal function. Eur J Cardio-thorac 2001; 20: 923-929. 